\title{
0 perdão como separação do ato. Hermenêutica e ressignificação do construto em Mt 18,21-22 e no discurso psicanalítico
}

\author{
Forgiveness as separation of the act. \\ Hermeneutic and resignification of the construct \\ in Mt 18,21-22 and in the psychoanalytical discourse
}

\section{Luís Henrique Eloy e Silva*}

Pontifícia Universidade Católica de Minas Gerais (PUC MINAS), Belo Horizonte, MG, Brasil Faculdade Jesuíta de Filosofia e Teologia (FAJE), Belo Horizonte, MG, Brasil

\section{Resumo}

O artigo estuda o tema do perdão no discurso de Jesus sobre a vida comunitária presente no capítulo 18 de Mateus e no discurso psicanalítico. Após a compreensão do perdão em Mt 18,21-22, em estreita consonância com o tema da correção fraterna, busca-se estudar os conceitos ressentimento e perdão como duas faces de um único

LHES: Doutor em Ciência Bíblica, e-mail: padreluishenrique@hotmail.com 
rosto que se conscientiza da doença do ressentimento e busca a cura pelo perdão. Enfim, a compreensão do perdão como separação do ato torna-se um ponto significativo de diálogo entre a psicanálise e a página do evangelho. Na clínica psicanalítica o perdão se dá pela consciência de que o outro pode falhar e que o sujeito, em relação à ferida, precisa se libertar para se curar; em Mt 18,21-22 o perdão se dá pela consciência do sujeito de que o outro, apesar de suas falhas e limites, não é somente seu próximo, mas é seu irmão em Cristo.

Palavras-chave: Hermenêutica Bíblica. Psicanálise. Perdão. Correção fraterna. Ressentimento.

\section{Abstract}

The paper studies the forgiveness theme in the discourse of Jesus on community life present in chapter 18 of Matthew and in psychoanalytic discourse. After understanding forgiveness in Mt 18,21-22, strictly in line with fraternal correction, the paper seeks to study the concepts "resentment and forgiveness" as two sides of a single face that comprehends the resentment as a disease and seeks the cure through pardon. Finally, the comprehension of forgiveness as an act of separation becomes a significant point of dialogue between psychoanalysis and the gospel page. In the psychoanalytic clinic, forgiveness is given by the knowledge that the other can fail and that the subject, in relation to the wound, must be free to reach the cure; in Mt 18,21-22 forgiveness is given by the consciousness of the subject that the other, despite his flaws and limits, is not only his neighbor, but his brother in Christ.

Keywords: Biblical Hermeneutics. Psychoanalysis. Forgiveness. Fraternal correction. Resentment. 


\section{Introdução}

O tema do perdão não se encontra comumente nos textos clássicos da psicanálise ${ }^{1}$. A razão talvez encontre justificativa pelo fato de que o perdão, enquanto conceito, seja quase sempre vinculado ao sentido religioso:

Não era de se esperar que um termo tão pregnante na tradição judaico-cristã pudesse ser alçado por Freud à guisa de conceito e, muito menos, um conceito que participasse de algum modo de sua proposta de tratamento para o sofrimento psíquico do sujeito neurótico (VERZTMAN, 2012, p. 252).

Ao contrário, o que é abundantemente desenvolvido nos textos da pesquisa psicanalítica é a metapsicologia da culpa (CAON, 1998, p. 82). Pelo fato da psicanálise não dar muita atenção a afetos que não eram averiguáveis em conflitos neuróticos, o foco nos processos inconscientes desencorajou o exame de afetos aparentemente conscientes e de fácil acesso pelo sujeito em análise, particularmente quando estes afetos pareciam ser uma resposta à realidade externa. O que se nota é que considerações sobre a culpa, ansiedade, depressão, ciúme, inveja, ódio, por exemplo, remontam a Freud e a Melanie Klein, mas um estudo sobre o perdão não mereceu a mesma atenção. Desde que Akhtar, em 2002, introduziu o tema do perdão na literatura analítica como uma emoção complexa com raízes conscientes e inconscientes, a atenção sobre o assunto, na investigação psicanalítica e na clínica, tem tomado outros rumos (SIASSI, 2007, p. 1440). Em termos gerais, nota-se que o interesse voltado para o estudo do perdão no discurso da psicologia e da psicanálise é recente (MCCULLOUGH; WORTHINGTON, 1999, p. 1143; KARGER, 2001, p. 16-22; SANTANA; LOPES, 2012, p. 620).

O intento desta reflexão não é versar sobre o perdão divino enquanto dom que Deus nos concede, nem tampouco discursar sobre o sujeito

1 Não se encontra o verbete "perdão", por exemplo, no vocabulário da Psicanálise de Laplanche \& Pontalis e nem mesmo no Dicionário Internacional da Psicanálise de Alain de Mijolla. Respectivamente, LAPLANCHE, J.; PONTALIS, J.-B. Vocabulário da Psicanálise. 4. ed. São Paulo: Martins Fontes, 2001; MIJOLLA, A. Dicionário Internacional da Psicanálise. Conceitos, noções, biografias, obras, eventos, instituições. Rio de Janeiro: Imago, 2002. 
que pede perdão ou que deve perdoar a si mesmo, ${ }^{2}$ mas sobre o sujeito que concede o perdão em sua dimensão intrapsíquica, desde o ponto de vista da psicanálise, mas também em sua dimensão de dom plena e conscientemente gratuito, desde o ponto da espiritualidade cristã segundo Mt 18,21-22. Em outras palavras, o foco é sobre quem viveu uma agressão, sente-se ferido, e se vê diante ou não da possibilidade de perdoar como um caminho. Inevitavelmente, ao sentir-se ferido, o sujeito se encontrará diante de uma via dupla: perdoar o agressor ou não. A decisão a favor do perdão ou contra ele gerará necessariamente consequências, para além da agressão sofrida, seja ela física, seja ela psíquica.

\section{0 perdão como percepção do ato}

No capítulo 18 do evangelho de Mateus encontra-se o quarto dos cinco grandes discursos que Jesus profere naquele evangelho. Particularmente aqui, para além da análise pormenorizada do discurso, é nosso intento notar que Jesus fala sobre dois elementos fundamentais para a construção da comunhão na comunidade cristã: a correção fraterna e o perdão. Entendamos o contexto: no início do capítulo, os discípulos se aproximam de Jesus para lhe perguntar sobre quem é o maior no Reino dos céus. Diante da questão posta, o campo semântico passa a versar sobre duas imagens: a imagem da criança (vv. 2.3.4.5) e a imagem do pequenino (vv. 4.6.10.14). A criança torna-se paradigma do discípulo. Ele é chamado a se assemelhar a ela e a acolhê-la por causa do nome de Jesus. O pequenino, por sua vez, surge com um sentido especificamente indicativo, ao fim da parábola da ovelha desgarrada, como figura do próprio

2 No campo da psicologia, há autores que não consideram o conceito de "perdão a si mesmo" como parte do discurso sobre o perdão stricto sensu, pois preferem chamar a isso de "aceitação de si" e não de perdão (MOLINARI; CECCARELLI, 2007, p. 243). Hannah Arendt, na mesma linha, dizia: "Ninguém pode perdoar-se a si próprio; no perdão, como na ação e no discurso, dependemos uns dos outros, aos quais aparecemos numa forma distinta que nós mesmos somos incapazes de perceber" (ARENDT, 1993, p. 255). Contudo, há discordâncias, como se pode ver na afirmação de Cavell que chama de autoperdão à superação de autoideais impossiveis e necessidades masoquistas de punição, quando o sujeito - visitado pela compaixão e pelo respeito a si mesmo - consegue se distinguir, enquanto pessoa, do ato que cometeu (CAVELL, 2003, p. 529). 
discípulo, que não pode se desviar do rebanho ou deixar que seus irmãos de comunidade se desviem (LUZ, 2003, p. 56).

Diante dessa preocupação presente no discurso de que nenhum dos pequeninos se perca, surge o tema da correção fraterna diretamente exposto por Jesus após a parábola da ovelha desgarrada (Mt 18,12-14), e o tema do perdão, suscitado pela pergunta do apóstolo Pedro (Mt 18,21).

Ainda que os temas da correção fraterna e do perdão estejam interligados, isso não deve ser visto como uma inferência simplesmente semântica. Ela é particularmente lexical e linguisticamente interconexa: em Mt 18,15a, que versa sobre a correção fraterna, temos a construção "hamartēsē ho adelphos sou" (se teu irmão pecar); em Mt 18,21b, que versa sobre o perdão, temos a construção "hamartēsei... ho adelphos mou" (pecará... meu irmão). Essa repetição dos verbos, ainda que o primeiro esteja no aoristo do subjuntivo (v. 15a) e o segundo no futuro do indicativo (v. $21 \mathrm{~b}$ ), interliga-os intimamente, pois, além de serem o mesmo verbo, relacionam o mesmo termo: ho adelphos (o irmão) que, no primeiro caso, é indicado pelo dêitico de segunda pessoa (teu) e, no segundo, pelo dêitico de primeira pessoa ( $\mathrm{meu}$ ). Naturalmente, o primeiro verbo, que está no aoristo do subjuntivo, denota a ausência de uma situação específica. O segundo verbo, todavia, está no futuro do indicativo, o que implica uma ação repetida e/ou possível (ZERWICK, 1994, p. 277), e o uso da frase preposicional "hamartēsei eis eme" (pecará contra mim) aponta para uma ofensa pessoal.

O tema da correção fraterna é indicado por um caminho pedagógico crescente desde a correção pessoal, e a sós, até a possibilidade da correção por meio da comunidade toda, caso o irmão não dê ouvido àquele que o chamou individualmente para corrigi-lo fraternalmente. Na frase presente no v. 15 "se ele te ouvir, ganhaste o teu irmão" encontra-se a motivação básica para a existência da correção fraterna: o irmão não pode se perder, ele precisa se reencontrar e na comunidade. Note-se que o verbo usado no v. 15 - "ganhaste" (ekerdēsas) - está no mesmo campo semântico do verbo usado no v. 14 - "não se perca" (apolètai).

O tema do perdão, por sua vez, é suscitado pelo questionamento de Pedro que deseja saber sobre a dimensão e os limites desse ato. O apóstolo pergunta a Jesus se o perdão estaria condicionado ao número sete. 
Obtém como resposta: "não te digo até sete, mas até setenta e sete vezes" (Mt 18,22), o que eleva a dimensão do perdão a uma disponibilidade sem limites (GNILKA, 1988, p. 218). O número 77 parece ser uma alusão a Gn 4,24 em que se fala da vingança limitada que pesa sobre o assassinato dos descendentes de Cain e de Lamec. Aqui, porém, o perdão ilimitado, em contraposição à vingança limitada, sobrepõe-se a ela e a supera (LUZ, 2003, p. 92).

Daqui inferimos algo essencial: Jesus não quer que nenhum dos pequeninos se perca (v. 14). Pelo vínculo léxico-semântico que se estabeleceu entre os temas da correção fraterna e do perdão, nota-se claramente que aí se encontra o caminho pedagógico querido pelo mestre em seu ensinamento sobre as relações intracomunitárias. Como assim? A correção fraterna é essencial na comunidade para que "o outro não se perca" (vai corrigi-lo). Por isso mesmo, a correção fraterna indica um empenho em direção ao outro, o foco é o outro, o seu bem, a fim de que não se perca. Já o perdão é igualmente essencial para que "eu não me perca". Diversamente, no caso do perdão, o foco é o próprio sujeito e não mais o próximo. Em outras palavras, na comunidade ninguém pode se perder. O caminho é a correção fraterna visando ao bem e ao reencontro com o outro, para que ele não se perca, e o perdão visando ao próprio bem e ao reencontro consigo mesmo para que o eu não se perca.

Note-se a estrutura magistral do discurso presente no esquema mateano:

Parábola da ovelha desgarrada (v. 12-14)

O tema da correção fraterna (v. 15-18): "se teu irmão pecar...”

JESUS NO CENTRO DA COMUNIDADE, reunida em seu nome (v. 19-20)

O tema do perdão (v. 21-22): "se meu irmão pecar contra mim..."

Parábola do mau servo que não perdoa (v. 23-35) 
A parábola da ovelha que se perdeu, e precisa ser novamente trazida ao rebanho, antecede o ensinamento sobre a correção fraterna. A parábola do mau servo que foi perdoado em sua dívida pelo rei, mas que não age semelhantemente com seu próximo, sucede ao ensinamento sobre o perdão ilimitado. Tanto no tema da correção fraterna quanto no tema do perdão encontra-se presente o elemento lexical "irmão". A diferença expressa pelos dêiticos de segunda pessoa (teu irmão) ou de primeira pessoa (meu irmão) são significativas, mas não interpretativas, pois dependem do sujeito que fala. Como no caso do tema da correção fraterna a iniciativa parte de Jesus, naturalmente o dêitico é de segunda pessoa: "se teu irmão pecar..."; no caso do tema do perdão, porém, é Pedro quem fala em referência a um questionamento posto por ele mesmo, logo o dêitico será de primeira pessoa. No entanto, a atenção de Jesus se volta para o conceito "irmão" a quem o discípulo é convocado a corrigir, para o bem do irmão, e a quem é convocado a perdoar, para o bem do próprio discípulo. Todavia, se por um lado se nota que a atenção se volta para o irmão, por outro se vê que o sujeito da correção fraterna é o mesmo do perdão: o "eu do discípulo" que, em sua realidade interior, em sua dimensão intrapsíquica, assume como caminho espiritual e ético conviver com o outro na comunidade onde se encontra Jesus que deseja que todos se salvem.

O esquema retórico, por sua vez, claramente completado em sua concentricidade estilística pelo conteúdo expresso nos versículos 19-20, corrobora o que foi apenas dito. Ali, nota-se que a comunidade, que promove a correção fraterna e o perdão ao próximo, vive da centralidade da compreensão de que Jesus se faz presente quando os irmãos vivem unidos em seu nome. Sendo assim, tanto a correção fraterna quanto o perdão passam a ter sentido por causa de Jesus e, nele alcançam seu significado e logram seu escopo. Em outras palavras, o próximo, que é meu irmão, não pode se perder e isso se alcança por meio do ato da correção fraterna; mas eu, igualmente, que sou irmão do meu próximo, também não posso me perder, e isso se dá por meio do ato do perdão. No entanto, que fique claro, em ambas as posturas, o ato da correção fraterna e do perdão necessitam do sim consciente, livre e amadurecido do "eu do discípulo" que, na responsabilidade da opção que o interliga ao projeto do mestre, decide corrigir o irmão ou perdoá-lo. 
Logo conclui-se que, para além das manifestações sócio-comunitárias do perdão e da possibilidade de reconciliação como exteriorização do ato de perdoar, o húmus original e fecundo do perdão é a realidade interior do discípulo segundo Mateus. Realidade essa que a psicanálise chama de dimensão intrapsíquica e que, por sua vez, a antropologia bíblica chamará de coração.

\section{0 perdão como consciência do ato}

No campo semântico do termo perdão, encontram-se mágoa, rancor, ódio, ressentimento, reconciliação etc. Como nosso foco põe-se no sujeito que recebeu o ato como ofensa e, assim, se vê diante da possibilidade ou impossibilidade de perdoar, acenaremos, devido ao objetivo deste artigo, somente aos termos mágoa, rancor e ressentimento.

Enquanto, etimologicamente, o termo mágoa, do latim mácula (mancha) indica algo realizado no ontem cuja marca, mancha, permanece no presente; o termo rancor, do latim ráncidus (rançoso, estragado, que fede) indica algo do ontem malconservado, mal integrado no hoje e, por isso, rançoso. O termo ressentimento, por sua vez formado pelo verbo "sentir" mais o prefixo "re", gravita semanticamente em torno da imagem de algo que retorna, que é sentido uma vez mais.

Em todos os três termos nota-se a presença da memória, pois a mancha remonta ao estado precedente a si própria, em que ela ainda não existia e, portanto, toca o sentido visual e, às vezes, tátil quando se tenta removê-la. Já o rancor remonta ao estado precedente do alimento em que ele possuía bom odor e boa aparência e, portanto, ao sentido visual, olfativo, gustativo e tátil. Enfim, o ressentimento é dos três termos aquele mais complexo e completo, pois sentir pode significar "perceber com os sentidos" e, portanto, re + sentir envolve trazer à memória a complexidade de sentimentos que podem ter sido vivenciados na pluralidade que envolve a visão, o olfato, a audição, o paladar e o tato, em síntese, o ser humano em sua múltipla e complexa dimensão afetiva.

Se não bastasse isso, o perdão é visto comumente como a superação do ressentimento (ENRIGHT; FREEDMAN; RIQUE, 1998, p. 46-47; 
HOLMGREN, 2012, p. 32). Em outras palavras, no quadrilátero semântico de Greimas, ressentimento e perdão estão intimamente relacionados como termos contrários. Alguns autores defendem que a vingança seria o contrário direto do perdão. Isso também é verdade, mas não nos esqueçamos de que a vingança é exteriorização do ressentimento transformado em ato. Todavia, como aqui partimos do pressuposto epistemológico do discurso do perdão como realidade intrapsíquica sem entrar em sua dimensão publicamente expressa ou social, tomamos como seu contrário direto o ressentimento, justamente por ser uma realidade intrapsíquica.

Como compreender o conceito ressentimento? Consiste na atitude de alguém em atribuir a outrem a responsabilidade causadora de seu sofrimento. Sendo assim, o ressentido se enquadra no paradigma do neurótico "com sua servidão inconsciente e sua impossibilidade de implicar-se como sujeito do desejo" (KEHL, 2004, p. 11). Por isso mesmo, é visto como o oposto do perdão, pois o ressentir indica o refluxo emocional, o retorno iterativo e interior do azedume afetivo que não é nem digerido nem expelido. O prefixo "re" acena, ainda que simbolicamente, a dois outros conceitos relacionados ao ressentimento: a reação não efetivada e o recalcamento. A reação falida, não posta em ato, gera a frustração e indica um impulso agressivo impedido de se efetivar. Como não houve uma reação à altura do efeito causado, o ressentido põe-se a acusar o ofensor ou a queixar-se dele. Ao atribuir a culpa ao outro que lhe causou o agravo, volta-se para o ofendido o eu das pulsões agressivas que, originalmente, estavam voltadas para o agressor de onde provém o olhar magoado e, portanto, velado pelo sofrimento psíquico com relação ao fato acontecido. Por outro lado, o recalcamento indica o impulso que foi impedido de se efetivar e, portanto, indica a consequência da reação não efetivada. Assim, o recalque surge como um passado mal integrado e processado. E como o inconsciente é atemporal, "o recalcado permanece vivo, preservado na forma de representações psíquicas relacionadas indiretamente ao vivido por meio de cadeias associativas" (KEHL, 2005, p. 170).

O estado mental do ressentido, na clínica psicanalítica, é associado a uma extrema sensibilidade ante uma frustração experimentada; a reação de dor e ira que relata é desproporcional ao fato causador; a desproporcionalidade deve-se ao fato de alguma antiga ferida (trauma, em 
grego) ainda aberta, não cicatrizada; existe, de sua parte, uma forte compulsão à repetição, reiterada e torturante; quase sempre, o ressentimento despertado é acompanhado por um desejo de vingança; por fim, pode ocorrer que o rancor seja cultivado ao longo de toda a vida (ZIMERMAN, 2010, p. 121).

Conforme Max Scheler, o ressentimento provoca uma deformação mais ou menos permanente, no que diz respeito aos valores do sujeito e à faculdade de julgamento (SCHELER, 1958, p. 14). Em outras palavras, a raiva, a cólera, a indignação não realizadas contra o agressor transformam-se em raiva e indignação contra si mesmo, causando o que Scheler chama de "envenenamento psicológico", característica de quem vive na condição de escravo (SCHELER, 1958, p. 19).

Na clínica, o ressentido dirige ao analista um lamento monótono contra uma injustiça, um agravo, uma ofensa da qual teria sido a vítima inocente. Bem depressa o analista percebe a impossibilidade de conduzir uma análise com alguém que se instala nessa posição; ainda que a ofensa tenha realmente ocorrido, ainda que um outro tenha de fato responsabilidade quanto ao dano que o ressentido denuncia, a atitude queixosa conduz o processo analítico a um beco sem saída. Se o sujeito está convicto de que sofre porque não pode esquecer o mal que lhe fizeram nem apagar as consequências do agravo, sua implicação no processo analítico fica comprometida. Isto é o que o ressentido quer, do ponto de vista das resistências próprias do narcisismo do eu. Mas não foi o que o conduziu a demandar a escuta de um analista (KEHL, 2004, p. 33-34).

Enquanto que para o ressentido quem está em questão é sempre o outro, ele alimenta a vingança. Não no sentido de pagar o mal com o mal, mas em desejar que o outro reconheça o mal que lhe causou. No fundo, não é que ele espere uma reparação do ato. De fato, não o quer, pois sua vida interior é alimentada pela perpetuação de sua condição de vítima por meio da qual o outro é mantido na condição de algoz. Não abre mão da condição de vítima, pois ao mesmo tempo em que isso o põe como alguém supostamente bom diante de outro que é mau, acaba realizando uma vingança adiada contra o outro. No fundo o ressentido não quer que o outro não exista ou morra; quer que seja castigado, que sofra (KANCYPER, 1994, p. 14). Se não o vê sofrendo aqui, corre o risco de usar da religião 
para alimentar o desejo de que seja castigado na eternidade pela justiça divina (KEHL, 2004, p. 21).

Diante disso, como entender, neste contexto discursivo, o tema do perdão?

Segundo Paul Gilbert, o termo perdoar é de origem medieval. Significa levar um dom à perfeição. O prefixo per indica a forma da ação perfeitamente completada. Por sua vez, o termo perfeição indica a perfeição do fato (factum). Já o termo dom (doar de perdoar), relaciona-se ao "deixar algo", "redimir uma dívida". Todos esses elementos levam à compreensão do perdão como profundamente gratuito, à renúncia total a algo que primariamente lhe seria devido (GILBERT, 2009, p. 280).

No entanto, o que se vê é que teóricos e pesquisadores tendem a concordar não sobre o que seja o perdão, mas justamente sobre o que ele não seja. No que tange ao tema da conceituação do construto há, pelo menos, três pontos de discordância: se o perdão seria um fenômeno intrapessoal ou interpessoal; se perdoar indicaria abrir mão de sentimentos, pensamentos ou comportamentos considerados negativos ou cultivar elementos positivos que venham a substituir os elementos negativos vivenciados anteriormente; se o perdão seria um evento realmente extraordinário, no sentido de que realiza transformações significativas na vida das pessoas ou se seria algo comum na experiência cotidiana das pessoas (SANTANA; LOPES, 2012, p. 623).

Pensamos que os questionamentos supracitados trazem em si pontos críticos quanto à compreensão do tema, mas não se contradizem. Depende se o ponto de vista está focado no indivíduo que oferece ou pede perdão, enquanto realidade eminentemente psicológica centrada no sujeito, ou no evento relacional cuja incompreensão gerou a ofensa dando início a uma ferida, o que demandaria uma análise fenomenológica enquanto percepção e compreensão do ato. Por outro lado, não necessariamente deveria o sentimento localizar-se no mesmo campo semântico do pensamento e do comportamento, pois, enquanto realidades presentes no sujeito, são bastante diversas. Sabe-se que nem sempre o pensamento condiz com o sentimento. Quantas vezes a mente arrazoa-se em processos que não são conformes aos sentimentos e nem tampouco ao comportamento! Contudo, pensar no perdão como algo comum da experiência 
cotidiana das pessoas não parece real, pois, como veremos, o nível pleno do perdão enquanto dom a ser concedido não é visto como uma característica conatural ao ser humano, mas como um exercício em termos psicológicos e éticos e como um dom, enquanto graça divina, no que diz respeito à compreensão cristã.

Por isso mesmo, compreendemos o perdão como realidade intrapessoal, da qual derivam os aspectos interpessoais e sociais do conceito. De fato, com Pargament pensamos que o perdão seja uma realidade intrapessoal e prossocial (PARGAMENT; MCCULLOUGH; THORESEN, 2001, p. 304). O perdão possui uma dimensão interpessoal, pois supõe-se a relação entre um que agride e outro que foi agredido; e intrapessoal, pois supõe-se que para haver perdão é necessário que haja uma elaboração interior ou intrapsíquica para que se possa pedir perdão ou dá-lo. Neste sentido, por ser um processo realizado unicamente no interior do indivíduo que sofreu o dano e em nada depende da posição do agressor (ANDREWS, 2000, p. 75-86), acreditamos que o perdão gera mudança no campo cognitivo, afetivo e comportamental do ofendido, mesmo quando não há reconciliação com o ofensor.

Segundo Enright, Freedman e Rique, perdoar é uma atitude moral por meio da qual o indivíduo abdica do direito ao ressentimento, a julgamentos e a comportamentos negativos com relação a quem causou injustamente uma ofensa, buscando, ao mesmo tempo, nutrir sentimentos de compaixão, misericórdia e, possivelmente, de amor para com o ofensor (ENRIGHT; FREEDMAN; RIQUE, 1998, p. 46-47). A compreensão parte do princípio de que houve uma ofensa considerada injusta e, diante de tal ato, o ofendido escolhe vencer o ressentimento, mesmo tendo direito a ele, alcançando, com tal gesto, uma nova consciência de si e do fato em três dimensões: afetiva, ao superar o ressentimento por meio da compaixão; cognitiva, ao superar a condenação pelo generoso respeito; comportamental, ao superar a indiferença ou tendência à vingança por meio de uma postura benévola com relação ao ofensor, em alguns casos com abertura inclusive à reconciliação (SANTANA; LOPES, 2012, p. 625). Todavia, perdoar não significa necessariamente reconciliar-se. Alguém pode perdoar e, mesmo assim, finalizar um relacionamento (WADE; WORTHINGTON, 2005, p. 160). 
Segundo Hannah Arendt o que distingue o ser humano de todos os outros seres são a ação e o discurso. Por meio da ação, o ser humano é capaz de comunicar a si mesmo e não somente algo de si. Nas palavras e atos dá-se a inserção no mundo humano, inserção que é um segundo nascimento em que o ser humano confirma e assume o fator singular de seu aparecimento físico e original. Agir é tomar iniciativa, iniciar e, portanto, imprimir movimento a algo (ARENDT, 1993, p. 189-190). Na condição de ser de ação, o ser humano enquanto sujeito do ato revela-se a si mesmo publicamente, pois a ação só é possível, segundo ela, na esfera pública (ARENDT, 1993, p. 193). Em outras palavras, por meio da ação o ser humano se exterioriza diante de seus semelhantes e se assemelha a eles. Já o discurso, por sua vez, distingue o sujeito de seu semelhante. Em suas palavras:

Se a ação, como início, corresponde ao fato do nascimento, se é a efetivação da condição humana da natalidade, o discurso corresponde ao fato da distinção e é a efetivação da condição humana da pluralidade, isto é, do viver como ser distinto e singular entre iguais (ARENDT, 1993, p. 191).

Nesse contexto de ação e discurso, o ser humano, permeado por incertezas e fragilidades, traz consigo a capacidade de causar sofrimento. Ela afirma:

Embora os homens sempre tenham sido capazes de destruir tudo o que fosse produzido por mãos humanas e, hoje, sejam capazes até de destruir aquilo que o homem não criou - a Terra e a natureza da Terra - nunca foram e jamais serão capazes de desfazer ou sequer controlar com segurança os processos que desencadeiam através da ação (ARENDT, 1993, p. 244).

Da impossibilidade de se desfazer o que se fez, embora não se soubesse nem se pudesse saber o que se fazia, nasce a faculdade de perdoar, a única solução possível para o problema da irreversibilidade de uma ação (ARENDT, 1993, p. 249). 


\section{0 perdão como separação do ato}

O verbo para indicar o perdão, usado por Mt 18,21, é aphiēmi. Já em época remota, o verbo está presente no grego e indica deixar, permitir, liberar. Em termos jurídicos, indica liberar alguém de uma posição jurídica, como por exemplo, ser liberado de uma prisão, de uma culpa ou de um castigo (BULTMANN, 1933, p. 507).

No Novo Testamento, o termo abarca o campo semântico do deixar, do abandonar, do separar-se. Particularmente, no evangelho de Mateus, aphiēmi, a título de exemplo, refere-se aos discípulos que deixam as redes, a barca e o pai para seguirem Jesus (Mt 4,20.22); à oferta deixada pelo discípulo diante do altar para antes reconciliar-se com o irmão (Mt 5,24); à orientação conforme a qual é preciso deixar também o manto para aquele que deseja levar a túnica (Mt 5,40); à febre que deixa a sogra de Pedro, após o toque de Jesus (Mt 8,15); ao pastor que deixa as noventa e nove ovelhas para buscar a que se perdeu (Mt 18,12); a Pedro que pergunta sobre qual será a recompensa para aqueles que deixaram tudo para seguir Jesus (Mt 19,27ss); aos fariseus que deixam Jesus após o ensinamento sobre a resposta do imposto a César (Mt 22,22); à construção do templo da qual não será deixada pedra sobre pedra (Mt 24,2); a Jesus que, após a prisão, é deixado por todos os discípulos (Mt 26,56). Somente em alguns casos relaciona-se especificamente ao perdão, como se pode ver a tradução na maioria das Bíblias: no contexto da oração do Pai-Nosso em que se pede ao Pai para perdoar as ofensas assim também como perdoamos a quem nos ofendeu $(\mathrm{Mt} \mathrm{6,12)} \mathrm{e,} \mathrm{ali,} \mathrm{o} \mathrm{tema} \mathrm{do} \mathrm{perdão}$ aparece como uma espécie de admoestação imperativa (Mt 6,14.15); no contexto da cura do paralítico que tem seus pecados perdoados (Mt 9,2.5.6); no contexto do ensinamento sobre o pecado contra o Espírito Santo, que não será perdoado (Mt 12,31-32); enfim, no contexto da parábola do rei que acerta contas com seus servos e decide perdoar a dívida de um deles que lhe pede um prazo (Mt 18,27.32), Jesus ensina que é preciso perdoar de coração o irmão (Mt 18,35).

A partir da compreensão etimológica grega do termo perdão conforme o texto de Mateus, com o uso de aphiēmi no sentido de deixar algo 
para trás, separar-se de, liberar-se de, identificamos uma compreensão significativa para o diálogo com a psicanálise.

A psicanálise é uma abordagem terapêutica fundada na escuta específica do discurso de alguém que busca a clínica a fim de superar um sofrimento psíquico (CUVILLIER, 2007, p. 161) e, portanto, deixá-lo para trás. No entanto, "é imprescindível que esta escuta analítica se desdobre numa escuta de si” (FOCHESATTO, 2011, p. 166). Superar um sofrimento psíquico, no caso do ressentimento, é alcançar a capacidade de perdoar, pressupondo a compreensão da mágoa, do rancor e do ato em si que causou o sofrimento. O perdão surge durante o processo analítico, segundo a psicanalista búlgara, Julia Kristeva, na esteira de Arendt, pelo trabalho de interpretação do ato, por meio do qual aquele que concede o perdão renasce para uma nova compreensão de si mesmo e de seu caminho (KRISTEVA, 2005, p. 281). Deste modo, entendemos que, pelo perdão, ocorre o renascimento do eu que permanecia como sombra de um eu que ainda não havia sido iluminado.

Hanna Arendt, por sua vez, entende bem que o sentido original do verbo aphiēmi não é perdoar, mas despedir e libertar e propõe a compreensão do perdão como "desobrigação do ato" (ARENDT, 1993, p.152). De alguma forma, ela entende que o perdão consiste, por um lado, no "desobrigar" o outro de ficar no lugar de quem errou ou transgrediu e, por outro lado, no "desobrigar-se" do próprio sujeito de permanecer como vítima ou como escravo do ato que deu início à ferida cultivada pelo ressentimento.

Ela defende que no mundo greco-romano ou em outra tradição que a precedeu não se encontra nenhuma compreensão de perdão como algo que acontece entre os homens, como a compreensão inaugurada por Jesus de Nazaré (ARENDT, 1993, p. 251). Nele encontra-se, portanto, uma nova compreensão, o que chamamos aqui de "evangelho do perdão". Jesus inicia o perdão como ação por meio de seu ensinamento, de seu testemunho e de sua entrega total na cruz: "Pai, perdoa-lhes, pois eles não sabem o que fazem" (Lc 23,34).

Ainda que o ofensor venha a pedir perdão, o ato permanecerá sempre irreversível. A reversibilidade não acontece no actus, mas no logos. Se é verdade que o ato não pode ser mais alterado, pois uma vez 
acontecido entra na irreversibilidade do tempo que se foi e que não pertence mais ao sujeito, a não ser à sua memória, que atualiza o sofrimento psíquico causado pelo ato no presente dramático do ressentimento, o logos, ao contrário, é a chave para o horizonte. Daí nasce o que chamamos de perdão como separação do ato, por meio do qual se dá a hermenêutica da ressignificação do ato.

Se o ato não pode ser mudado, a hermenêutica que o sujeito estabelece do ato pode e deve mudar, não a partir do ato, que permanece no passado inalcançável, mas a partir do horizonte que se descortina a partir do ato e, muitas vezes, apesar dele. De fato, como já havia intuído Arendt, o perdão não se vincula ao esquecimento, mas à inscrição, desobrigação e liberdade para novamente agir. "Mudar de ideia significa saber o que não se sabia, o que só é possível através do trabalho da memória e nunca através do esquecimento" (VERZTMAN, 2012, p. 252). O perdão dá um basta ao acontecimento e abre o caminho para a liberdade, pois diante do irreparável, a memória decide optar não pela doença que é a lembrança incessante do mesmo fato, mas pela cura que sinaliza o nascimento e a possibilidade de que tudo possa recomeçar, de outra forma (WIESENTHAL, 2004, p. 160).

Quando não ocorre o perdão, o sujeito permanece preso à ação é não se vê diante da possibilidade de tornar-se um novo iniciador e, portanto, separar-se do que o faz sofrer e que, de certa forma, o prende.

Neste sentido é preciso entender a etimologia do verbo "separar" do qual provém consequentemente o substantivo "separação". A partícula "se" acrescenta à palavra composta a ideia de afastamento do ato e traz à consciência a imagem de que o ato permaneceu no passado e lá deve ficar. Indica não mais uma compreensão povoada pelo ressentimento passivo, magoado e rancoroso que, de alguma forma, vive da insalubridade da memória que, qual água estagnada, não se move rumo à liberação do que a constitui doentiamente. Acena ao abandono do que precisa ficar para trás e indica uma abertura ao agir renovador e reiniciador de um novo caminho, agora fecundado pela hermenêutica de um novo olhar cujo solo é a escuta, sobretudo, do si mesmo. Escuta imprescindível e intransferível, que na responsabilidade da assunção dos próprios sentimentos os acolhe, compreende e ressignifica a fim de que não caiam no padrão do 
ressentimento em que o sujeito, ao se alimentar do veneno, fica à espreita ingênua de que o veneno que acabou de ingerir possa fazer mal ao outro que o ofendeu. E com o tempo dá-se conta de que o único prejudicado não é o outro, mas o si mesmo envenenado pelas teias do ressentimento que o povoa.

\section{Considerações finais}

Se é verdade que na psicanálise enquanto reflexão, mas também enquanto atividade clínica, o perdão é parte conclusiva de um ciclo terapêutico e abandono de um itinerário antes marcado pela mágoa, pelo rancor, pelo ódio, pelo desejo de vingança e, enfim, pelo ressentimento que em si mesmo sintetiza a constelação complexa desses afetos e possivelmente de outros, o mesmo ocorre na compreensão cristã do perdão segundo Mt 18,21-22, com uma diferença que põe o cristianismo numa perspectiva mais ampla. Enquanto a psicanálise vê o perdão como caminho terapêutico e, portanto, de cura, o cristianismo dá um passo ulterior. Para o cristianismo o perdão é terapêutico sim, mas é sobretudo redentor e insere o cristão numa dimensão de comunhão de amor com o outro que não é somente o outro que o fere, que o machuca e que é falho, mas que é seu irmão em Cristo.

Com efeito, o caminho do retorno a si mesmo como fator integrador de um novo início passa necessariamente, na vida comunitária, pela superação da culpa e do ressentimento. A separação do ato, contudo, é possibilidade de um novo horizonte que, diante da irreversibilidade do ato passado, constrói um novo amanhã no hoje. Entre o passado e o futuro, no hoje que interliga a memória e o desejo de um novo sentido situa-se "o si mesmo", o sujeito que à escuta não só de si, mas, particularmente, do mestre Jesus e de seu ensinamento, entende o perdão como caminho necessário, pessoal e intransferível para não se perder a si mesmo e compreender que o outro, de quem não quer mais guardar ressentimento e ao qual oferece o perdão em sua inteireza, é seu irmão. 
Foi-se e ficou!

Foi-se como o que precisa ir; ficou como o que precisa ficar. Ah! O que foi não me pertence mais... O que ficou, sim! E que permaneça, mas como separação do ato, como horizonte de um novo percurso! (Eloy e Silva)

\section{Referências}

ANDREWS, M. Forgiveness in context. Journal of Moral Education, n. 29, p. 7586, 2000.

ARENDT, H. A condição humana. São Paulo: Forense Universitária, 1993.

BULTMANN, R. aphiēmi. In: KITTEL, G; FRIEDRICH, G. (Ed.). Theologisches Wörterbuch zum Neuen Testament. Stuttgart: Kohlhammer Verlag, 1933, I. p. 506-509.

CAON, J. L. Metapsicologia do perdão. Veritas, Porto Alegre, v. 43, n. 1, p. 81-90, Mar. 1998.

CAVELL, M. Freedom and forgiveness. International Journal of Psycho-Analysis, v. 84, n. 3, p. 515-531, 2003.

CUVILLIER, E. Bible et Psychanalyse. Quelques éléments de réflexion. Études Théologiques et Religieuses, n. 2, p. 159-177, 2007.

ENRIGHT, R.D.; FREEDMAN, S; RIQUE, J. The Psychology of Interpersonal Forgiveness. In: ENRIGHT, R.D; NORTH, J. (Ed.). Exploring Forgiveness. Madison: University of Wisconsin Press, 1998. p. 46-62.

FOCHESATTO, W. P. F. A cura pela fala. Estudos de Psicanálise, n. 36, p. 165-172, 2011.

GILBERT, P. Violence et compassion. Essai sur l'authenticité d'être. Paris: Éditions du Cerf, 2009. 
GNILKA, J. Il Vangelo di Matteo. Parte seconda. Brescia: Paideia Editrice, 1988.

HOLMGREN, M. R. Forgiveness and retribution. Responding to wrongdoing. Cambridge: Cambridge University Press, 2012.

KANCYPER, L. Ressentimento e remorso. São Paulo: Casa do Psicólogo, 1994.

KARGER, A. Verzeihung - Reconsiliation - Versöhnung. Versuch der Differenzierung verschiedener Konzepte. In: KARGER, A. (Ed.). Vergessen, vergelten, vergeben, versöhnen? Weiterleben mit dem Trauma. Psychoanalytische Blätter, 30, Göttingen: Vandenhoeck \& Ruprecht, 2001. p. 12- 31.

KEHL, M. R. O ressentimento camuflado da sociedade brasileira. Novos Estudos, v. 71, março, p. 163-180, 2005.

KEHL, M. R. Ressentimento. Rio de Janeiro: Casa do Psicólogo, 2004.

KRISTEVA, J. La haine et le pardon: pouvoirs et limites de la psychanalyse III. Paris: Fayard, 2005.

LAPLANCHE, J.; PONTALIS, J.-B. Vocabulário da Psicanálise. 4. ed. São Paulo: Martins Fontes, 2001.

LUZ, U. El Evangelio según San Mateo. Mt 18-25 (vol. III). Salamanca: Ediciones Sígueme, 2003.

MCCULLOUGH, M. E.; WORTHINGTON, E.L. Religion and the Forgiving Personality. Journal of Personality, v. 67, No. 6, p. 1141-1164, 1999.

MIJOLLA, A. Dicionário Internacional da Psicanálise. Conceitos, noções, biografias, obras, eventos, instituições. Rio de Janeiro: Imago, 2002.

MOLINARI, E.; CECCARELLI, A. Il processo del perdono: aspetti psicologici. Rivista di Psicologia Clinica. n. 3, p. 242-253, 2007.

PARGAMENT, K.I.; MCCUlLOUGH, M. E.; THORESEN, C.E. The Frontier of forgiveness; Seven directions for psychological study and practice. In: MCCULLOUGH, M. E; PARGAMENT, K.I.; THORESEN, C.E. (Ed.). Forgiveness: Theory, research and practice. New York: Guilford Press, 2000. p. 299-319. 
SANTANA, R. G.; LOPES, R. F. F. Aspectos conceituais do perdão no campo da psicologia. Psicologia, Ciência e Profissão. v. 32, n. 3, p. 618-631, 2012.

SCHELER, M. L'homme du ressentiment. Paris: Gallimard, 1958.

SIASSI, S. Forgiveness, acceptance and the matter of expectation. The International Journal of Psycho-Analysis. v. 88, n. 6, p. 1423-1440, 2007.

VERZTMAN, J. O Perdão é um tema que interessa à Psicanálise? In: VERZTMAN, J.; HERZOG, R.; PINHEIRO, T.; PACHECO-FERREIRA, F. (org.). Sofrimentos narcísicos. Rio de Janeiro: Cia. de Freud, 2012. p. 250-312.

WADE, N. G.; WORTHINGTON, E.L. In search of a common core: a content Analysis of interventions to promote forgiveness. Psychotherapy: Theory, Research, Practice, Training. v. 42, n. 2, p. 160-177, 2005.

WIESENTHAL, S. Les fleurs du soleil. Paris: Albin Michel, 2004.

ZERWICK, M. Biblical Greek. English edition adapted from the Fourth Latin Edition by Joseph Smith. Roma: Editrice Pontificio Istituto Biblico, 1994.

ZIMERMAN, D. E. Os quatro vínculos: amor, ódio, conhecimento e reconhecimento na psicanálise e em nossas vidas. Porto Alegre: Artmed, 2010.

Recebido: 30/10/16

Received: 10/30/16

Aprovado: $15 / 02 / 17$

Approved: 02/15/17 